\title{
Prevalence of overweight and obesity among school-aged children in urban, rural and mountain areas of the Veneto Region, Italy
}

\author{
Chiara Bertoncello ${ }^{1}$, Romina Cazzaro ${ }^{1}$, Anna Ferraresso ${ }^{1}$, Roberto Mazzer $^{2}$ and \\ Giorgio Moretti ${ }^{1, *}$ \\ 'Department of Environmental Medicine and Public Health, University of Padua, via Loredan 18, I-35131 \\ Padova, Italy: ${ }^{2}$ Food and Nutrition Service, Health Authority no. 7, Conegliano, Italy
}

Submitted 26 January 2007: Accepted 23 July 2007: First published online 17 October 2007

\begin{abstract}
Objective: To define the prevalence of overweight and obesity among schoolaged children resident in mountain areas, rural areas and urban areas.

Design, setting and subjects: The sample ( $n=12832 ; 50.7 \%$ boys) included 9- and 11-year-old children of the Veneto Region of north-east Italy. Overweight and obesity status were determined using the International Obesity Task Force cut-off points for body mass index. The prevalence of overweight and obese subjects was calculated with a confidence interval of 95\%. The Mantel-Haenszel method was used to compare the combined prevalence of overweight and obesity among children resident in mountain areas, rural areas and urban areas.

Results: Among boys the prevalence of overweight was 21.06\%, while obesity prevalence was 5.92\%; among girls overweight prevalence was $21.30 \%$, while obesity prevalence was $5.15 \%$. The prevalence was higher among 11-year-old boys (odds ratio $(\mathrm{OR})=1.19 ; 95 \%$ confidence interval $(\mathrm{CI}): 1.06-1.33$ ) and 9-yearold girls ( $\mathrm{OR}=1.13 ; 95 \% \mathrm{CI}: 1.01-1.26)$. Children resident in rural areas presented a higher risk of overweight and obesity compared with children resident in mountain areas (Mantel-Haenszel OR $=1.27 ; 95 \%$ CI: $1.13-1.42 ; \chi^{2}=17.55$; $P<0.0001$ ) and in urban areas (Mantel-Haenszel OR $=1.18 ; 95 \%$ CI: $1.07-1.31$; $\left.\chi^{2}=10.39 ; P<0.001\right)$.

Conclusions: A relevant prevalence of overweight and obesity was found; the excess weight concerns one child in four. There are differences linked to different geographical areas that must be further investigated.
\end{abstract}

\section{Keywords \\ Overweight \\ Obesity \\ Schoolchildren}

The prevalence of overweight and obesity is increasing rapidly, especially in higher-income countries ${ }^{1,2}$. Body weight and body composition in childhood are important determinants of overweight in adulthood $^{3-6}$. There is increasing evidence that the development of overweight and obesity in children has deleterious social and health consequences $^{7}$. In Italy, 15-25\% of children under 18 years of age are already classed as overweight or obese $^{8-12}$.

In describing the nutritional status of a population, the body mass index (BMI) represents the most complete indicator and, at the same time, is the easiest to use. In particular, it is known that in all infant ages body fat is better correlated with the BMI than with other indicators $^{13-15}$. The International Obesity Task Force (IOTF) recommends cut-off points for BMI in childhood that are based on international data and linked to the widely accepted adult cut-off points ${ }^{16}$. In order to effect appropriate public health measures for the treatment and prevention of childhood overweight and obesity, accurate estimates of these prevalences are required. The aim of the present study was to provide regional estimates for overweight and obesity in school-aged children residing in Veneto Region, Italy.

\section{Subjects and methods}

Veneto is a region in the north-east of Italy with a population of 4527694 inhabitants in $2001^{17}$; children 9 years of age who attend 3rd year primary schools (born in 1995) numbered 39525 and children of 11 years of age who attend 5th year primary schools (born in 1993) numbered 39825.

Relevant data of primary schools (name, location and number of students attending the 3rd and 5th years) were 
obtained from the local education authorities. Schools were randomly sampled in the reference territory of the local health authorities until reaching $20 \%$ of the students of the 3 rd year and of the 5 th year.

The 'Service of Food Hygiene and Nutrition' of each local health authority registered measurements of the children's weight and height during the period April-June 2004. In order to acquire the competences necessary for correct registration of the anthropometric measurements, the people involved - 45 operators in all - participated in the 'Course in surveying anthropometrical indexes' held at the Department of Environmental Medicine and Public Health at Padua University.

The same height stand and scales were used throughout the study. Weight was measured to the nearest $0.1 \mathrm{~kg}$ using electronic scales (Wunder). Height was measured to the nearest $0.1 \mathrm{~cm}$ using a portable stadiometer (Seca). The instruments used were calibrated before every measuring session. During the measuring the children wore underclothes only and were barefoot.

The measurements obtained were registered and sent to the Laboratory of Environmental Epidemiology at the Department of Environmental Medicine and Public Health at Padua University.

BMI was calculated as body weight divided by the square of body height. To define overweight and obesity, the sex- and age-specific BMI cut-offs recommended by the IOTF were used ${ }^{16}$. This is based on average percentiles, which equate to a BMI of 25 or $30 \mathrm{~kg} \mathrm{~m}^{-2}$ at age 18 years for overweight or obesity, respectively. Here, obesity is defined as BMI on or above the obesity cut-off, while overweight is a BMI on or above the overweight cut-off and below the obesity cut-off.

\section{Statistical methods}

The sample examined was subdivided into three groups representing the different realities of the Veneto Region: rural areas, urban areas and mountain areas (local communes of the mountain territory identified with regional laws $^{18}$ ).

The results are presented as crude cross-sectional prevalence (95\% confidence limits) of overweight and obesity. The odds ratio and 95\% confidence interval (OR, 95\% CI) was used for the univariate comparisons. The Mantel-Haenszel method was used to examine differences between different geographical areas stratifying the sample by sex and age.

\section{Results}

The total number of measurements taken in Veneto was 13234 (6510 girls and 6724 boys), the number of valid (corrected by year born) measurements was 12832 (6311 girls and 6521 boys). Subjects aged 9 years numbered
Table 1 The characteristics of the sample

\begin{tabular}{lcc}
\hline & $n$ & $\%$ \\
\hline & 12832 & \\
Sex & & \\
$\quad$ Boys & 6521 & 50.8 \\
$\quad$ Girls & 6311 & 49.2 \\
Age (years) & & \\
$\quad 9(8.5-9.5)$ & 6508 & 50.7 \\
$\quad 11$ (10.5-11.5) & 6345 & 49.4 \\
$\begin{array}{l}\text { Territory } \\
\quad \text { Mountain areas }\end{array}$ & 2163 & 16.9 \\
$\quad$ Rural areas & 7972 & 62.1 \\
$\quad$ Urban areas & 2697 & 21.0 \\
\hline
\end{tabular}

6508 (16.88\% of the same aged Veneto population), subjects aged 11 years numbered 6345 (16.37\% of the same aged Veneto population). The characteristics of the sample are summarised in Table 1.

Among boys the prevalence of overweight was 21.06\%, while obesity prevalence was 5.92\%; among girls overweight prevalence was $21.30 \%$, while obesity prevalence was $5.15 \%$. Tables 2 and 3 show the prevalence of overweight and obesity among our population subdivided by age, sex and geographical area.

When comparing the results according to sex and age, a significant difference was observed for: the prevalence of overweight, which was higher among 11-year-old boys (OR $=1.21$; 95\% CI: 1.09-1.36) than 9-year-old boys; the prevalence of overweight plus obesity, which was higher among boys aged 11 years ( $\mathrm{OR}=1.19$; 95\% CI: $1.06-1.33$ ) than girls of the same age; and the prevalence of overweight plus obesity, which was higher among girls aged 9 years $(\mathrm{OR}=1.13$; 95\% CI: $1.01-1.26)$ than among boys of the same age.

These results suggest a positive trend with age in boys and a negative trend in girls. Comparison of the combined prevalence of overweight and obesity in the three different geographical areas revealed a higher risk for children resident in rural areas, both in relation to those resident in mountain areas ${ }^{18}$ (Mantel-Haenszel OR = 1.27; 95\% CI: $\left.1.13-1.42 ; \chi^{2}=17.55 ; P<0.0001\right)$ and those resident in urban areas (Mantel-Haenszel $\mathrm{OR}=1.18$; 95\% CI: $\left.1.07-1.31 ; \chi^{2}=10.39 ; P<0.001\right)$. Comparing the combined prevalence of overweight and obesity among children from urban areas and from mountain areas, no significant differences were found.

\section{Discussion}

The results obtained in this study are the most recent and indeed the only available data on overweight and obesity in children of Veneto Region. These data, concerning representative samples of 9- and 11-year-old children, provide an important baseline from which to study future trends in overweight and obesity, to address preventive 
Table 2 Prevalence of overweight and obesity* according to sex and age

\begin{tabular}{|c|c|c|c|c|c|c|c|}
\hline & \multirow[b]{2}{*}{$N$} & \multicolumn{3}{|c|}{ Overweight } & \multicolumn{3}{|c|}{ Obesity } \\
\hline & & $n$ & $\%$ & $95 \%$ confidence interval & $n$ & $\%$ & $95 \%$ confidence interval \\
\hline \multicolumn{8}{|l|}{ Boys } \\
\hline 9-year-olds & 3325 & 634 & 19.1 & $17.7-20.4$ & 201 & 6.0 & $5.2-6.9$ \\
\hline 11-year-olds & 3194 & 739 & 23.1 & $21.7-24.6$ & 185 & 5.8 & $5.0-6.6$ \\
\hline \multicolumn{8}{|l|}{ Girls } \\
\hline 9-year-olds & 3183 & 694 & 21.8 & 20.4-23.2 & 178 & 5.6 & $4.8-6.4$ \\
\hline 11-year-olds & 3151 & 655 & 20.8 & $19.4-22.2$ & 148 & 4.7 & $4.0-5.4$ \\
\hline
\end{tabular}

${ }^{*}$ Overweight is defined as body mass index (BMI) on or above the overweight cut-off and below the obesity cut-off of the International Obesity Task Force (IOFT); obesity is defined as BMI on or above the IOTF obesity cut-off.

Table 3 Prevalence of overweight and obesity* according to sex, age and geographical area

\begin{tabular}{|c|c|c|c|c|c|c|c|}
\hline & \multirow[b]{2}{*}{$N$} & \multicolumn{3}{|c|}{ Overweight } & \multicolumn{3}{|c|}{ Obesity } \\
\hline & & $n$ & $\%$ & $95 \%$ confidence interval & $n$ & $\%$ & $95 \%$ confidence interval \\
\hline \multicolumn{8}{|l|}{ Boys } \\
\hline \multicolumn{8}{|l|}{ 9-year-olds } \\
\hline Mountain areas & 528 & 76 & 14.4 & $11.4-17.4$ & 30 & 5.7 & $3.7-7.7$ \\
\hline Rural areas & 2098 & 420 & 20.0 & $18.3-21.7$ & 136 & 6.5 & $5.4-7.5$ \\
\hline Urban areas & 699 & 138 & 19.7 & $16.8-22.7$ & 35 & 5.0 & $3.4-6.6$ \\
\hline \multicolumn{8}{|l|}{ 11-year-olds } \\
\hline Mountain areas & 542 & 118 & 21.8 & $18.3-25.2$ & 21 & 3.9 & $2.3-5.5$ \\
\hline Rural areas & 1965 & 486 & 24.7 & $22.8-26.6$ & 124 & 6.3 & $5.2-7.4$ \\
\hline Urban areas & 689 & 135 & 19.6 & $16.6-22.6$ & 40 & 5.8 & $4.1-7.6$ \\
\hline \multicolumn{8}{|l|}{ Girls } \\
\hline \multicolumn{8}{|l|}{ 9-year-olds } \\
\hline Mountain areas & 528 & 113 & 21.4 & $17.9-24.9$ & 34 & 6.4 & $4.4-8.5$ \\
\hline Rural areas & 2014 & 451 & 22.4 & $20.6-24.2$ & 114 & 5.7 & $4.7-6.7$ \\
\hline Urban areas & 640 & 130 & 20.3 & $17.2-23.4$ & 30 & 4.7 & $3.1-6.3$ \\
\hline \multicolumn{8}{|l|}{ 11-year-olds } \\
\hline Mountain areas & 565 & 101 & 17.9 & $14.7-21.0$ & 18 & 3.2 & $1.7-4.6$ \\
\hline Rural areas & 1895 & 411 & 21.7 & $19.8-23.6$ & 103 & 5.4 & $4.4-6.5$ \\
\hline Urban areas & 669 & 139 & 20.8 & $17.7-23.9$ & 26 & 3.9 & $2.4-5.4$ \\
\hline
\end{tabular}

${ }^{*}$ Overweight is defined as body mass index (BMI) on or above the overweight cut-off and below the obesity cut-off of the International Obesity Task Force (IOFT); obesity is defined as BMI on or above the IOTF obesity cut-off.

interventions and to monitor the impact of public health strategies.

The research gave to all Services of Food Hygiene and Nutrition of Veneto Region the opportunity to acquire a rigorous and reproducible methodology that will be useful to future studies.

This paper has highlighted a high prevalence of overweight and obese children in Veneto Region, in line with the high prevalence registered in southern European countries $^{7,19-22}$. A lower prevalence in the northern regions of Italy with respect to that of central Italy ${ }^{12}$ is confirmed.

Similar levels of overweight plus obesity were seen in boys and girls. Comparing the prevalence of overweight plus obesity by gender and age group, the results suggested a positive trend with age in boys and a negative trend in girls. However, there is a relationship between puberty and BMI that may affect the performance of the cut-off points in the age group considered. Pubertal growth acceleration starts with hormonal and physical modifications in children between the ages of 8 and
12 years, in both genders. Several studies have documented a change in body fat as girls progress through puberty, during which time a larger fat deposition is described. In addition, obesity is an important contributing factor to the earlier onset of puberty in girls. In boys puberty is characterised by a greater development of skeletal-muscle mass ${ }^{8,23,24}$.

A significantly higher prevalence of overweight and obesity was found in children living in rural areas when comparing the combined prevalence of overweight and obesity by residential location (urban, rural, mountainous). The highest prevalence of overweight and obesity in rural areas has been described by other authors ${ }^{25,26}$; in particular, it was identified for Italian adults.

Differences in overweight and obesity prevalence are related to many variables such as dietary intake, physical activity, family history of obesity and social class; these factors were not investigated in the present study, making it inappropriate to discuss possible causes of overweight and obesity in this population ${ }^{27-29}$. In particular, the 
reason for the geographical differences is not entirely clear at present.

\section{Conclusion}

This is the first time that the prevalences of overweight and obesity have been estimated in children in Veneto Region. These data are essential in order to monitor trends in prevalence and will form the basis for public health initiatives designed to increase children's health. The strength of the study lies in the large sample size. More research is needed to determine the origin of differences observed by geographical area.

\section{Acknowledgements}

The authors wish to thank all co-workers, teachers, parents and children. They are grateful to the clinical and administrative staff of the Veneto Region's health authorities. Thanks also to the Veneto Region Administration for financial support.

\section{References}

1 Lobstein T, Frelut ML. Prevalence of overweight among children in Europe. Obesity Reviews 2003; 4: 195-200.

2 Jolliffe D. Extent of overweight among US children and adolescents from 1971 to 2000. International Journal of Obesity and Related Metabolic Disorders 2004; 28: 49.

3 Rimm IJ, Rimm A. Association between juvenile onset of obesity and severe adult obesity in 73532 women. American Journal of Public Health 1976; 66: 479-89.

4 Rolland-Cachera MF, Deheeger M, Bellisle F, Sempe M, Guilloud-Bataille M, Patoise E. Adiposity rebound in children: a simple indicator for predicting obesity. American Journal of Clinical Nutrition 1984; 39: 129-35.

5 Guo SS, Chumlea WC. Tracking of body mass index in children in relation to overweight in adulthood. American Journal of Clinical Nutrition 1999; 70(Suppl.): S145-8.

6 Janssen I, Katzmarzyk PT, Srinivasan SS, Chen W, Malina RM, Bouchard C, et al. Utility of childhood BMI in the prediction of adulthood disease: comparison of national and international references. Obesity Reviews 2005; 13: 1106-15.

7 Livingstone B. Epidemiology of childhood obesity in Europe. European Journal of Pediatrics 2000; 159(Suppl. 1): S14-34.

8 Maffeis C, Talamini G, Tatò L. Influence of diet, physical activity and parent's obesity on children adiposity: a fouryear longitudinal study. International Journal of Obesity and Related Metabolic Disorders 1998; 22: 758-64.

9 De Vito E, La Torre G, Langiano E, Berardi D, Ricciardi G. Overweight and obesity among school children in Central Italy. European Journal of Epidemiology 1999; 15: 649-54.

10 Gnavi R, Spagnoli TD, Gallotto C, Pugliese E, Carta A, Cesari L. Socioeconomic status, overweight and obesity in prepubertal children: a study in an area of Northern Italy. European Journal of Epidemiology 2000; 16: 797-803.

11 Pomponi G, Piccinelli R, Leclercq C, Morino G, Ciarella G, Censi L. Monitoraggio dello stato nutrizionale in età evolutiva nel Lazio. Proceedings of the XXXI Congress. Nazionale SINU, Napoli, 15-17 March 2000. Giornale Italiano di Nutrizione Clinica e Metabolismo 2000; 9: 49.
12 Celi F, Bini V, De Giorgi G, Molinari D, Faraoni F, Di Stefano G, et al. Epidemiology of overweight and obesity among school children and adolescents in three provinces of central Italy, 1993-2001: study of potential influencing variables. European Journal of Clinical Nutrition 2003; 57: 1045-51.

13 Cole TJ. Weight stature indices to measure underweight, overweight and obesity. In: Himes JH, ed. Anthropometric Assessment of Nutritional Status. New York: Wiley-Liss, 1991; 83-111.

14 Daniels SR, Khoury PR, Morrison JA. The utility of body mass index as a measure of body fatness in children and adolescents: differences by race and gender. Pediatrics 1997; 99: 804-7.

15 Scholler DA. Use of the body mass index (BMI) as measure of overweight in children and adolescents. Journal of Pediatrics 1998; 132: 191-3.

16 Cole TJ, Bellizzi MC, Flegal KM, Dietz WH. Establishing standard definition for child overweight and obesity worldwide international survey. British Medical Journal 2000; 320: 1240-3.

17 Istituto Nazionale di Statistica (Istat). Censimento 2001 [online], 2003. Available at http://censimenti.istat.it/html/ pop_home.asp. Accessed 7 January 2004.

18 Legge Regionale 3 luglio 1992, no. 19. Norme sull'istituzione e il funzionamento delle comunità montane. BUR n $72 / 1992$.

19 Chinn S, Rona RJ. Prevalence and trend in overweight and obesity three cross sectional studies of British children, 1974-94. British Medical Journal 2001; 322: 24-30.

20 Krassas GE, Tzotzas T, Tsametis C, Kostantinidis T. Prevalence and trends in overweight and obesity among children and adolescents in Thessaloniki, Greece. Journal of Pediatric Endocrinology \& Metabolism 2001; 14(Suppl. 5): S1319-26.

21 Karayiannis D, Yannakoulia M, Terzidou M, Sidossis LS, Kokkevi A. Prevalence of overweight and obesity in Greek school-aged children and adolescents. European Journal of Clinical Nutrition 2003; 57: 1189-92.

22 Will B, Zeeb H, Baune BT. Overweight and obesity at school entry among migrant and German children: a cross sectional study. BMC Public Health 2005; 5: 45.

23 Bini V, Celi F, Berioli MG, Bacosi ML, Stella P, Giglio P, et al. Body mass index in children and adolescents according to age and pubertal stage. European Journal of Clinical Nutrition 2000; 54: 214-18.

24 Kaplowitz PB, Slora EJ, Wasserman RC, Pedlow SE, Herman-Giddens ME. Earlier onset of puberty in girls: relation to increased body mass index and race. Pediatrics 2001; 108: 347-53.

25 Plotnikoff RC, Bercovitz K, Loucaides CA. Physical activity, smoking, and obesity among Canadian school youth. Comparison between urban and rural schools. Canadian Journal of Public Health 2004; 95: 413-18.

26 Istituto Nazionale di Statistica (Istat) - Settore Famiglie e Società. Fattori di rischio e tutela della salute, Indagine Multiscopo sulle famiglie 'Condizioni di salute e ricorso ai servizi sanitari' Anni 1999-2000. Roma: Istat, 2002.

27 De Spiegaelere M, Dramaix M, Hennart P. The influence of socioeconomic status on the incidence and evolution of obesity during early adolescence. International Journal of Obesity and Related Metabolic Disorders 1998; 22: 268-74.

28 Wang Y. Cross-national comparison of childhood obesity: the epidemic and the relationship between obesity and socioeconomic status. International Journal of Epidemiology 2001; 30: 1129-36.

29 Haas JS, Lee LB, Kaplan CP, Sonneborn D, Phillips KA, Liang SY. The association of race, socioeconomic status, and health insurance status with the prevalence of overweight among children and adolescents. American Journal of Public Health 2003; 93: 2105-10. 